\title{
CONTROVERSIES AND LIMITATIONS IN THE DIAGNOSIS OF CHRONIC OBSTRUCTIVE PULMONARY DISEASE
}

\author{
Alejandro Reyes-García, luis Torre-Bouscoulet and Rogelio Pérez-Padilla* \\ Department of Research on Tobacco and COPD, Instituto Nacional de Enfermedades Respiratorias Ismael Cosío Villegas, \\ Mexico City, Mexico
}

\begin{abstract}
Chronic obstructive pulmonary disease (COPD) is a major cause of chronic morbidity and mortality worldwide. While the cut-off point to define airflow obstruction has been controversial, it is widely accepted that the spirometry test is vital, as well as performing it after using a bronchodilator. The 6 -second spirometry and the forced expiratory volume in 1 second/forced expiratory volume in 6 seconds $\left(\mathrm{FEV}_{1} / \mathrm{FEV}_{6}\right)$ have demonstrated validity for defining obstruction, and it would be advisable to incorporate them in the definitions of obstruction. Another relevant issue is that spirometry with borderline obstruction can vary over time, changing to above or below the cut-off point. Thus, surveillance should be considered over time, repeating the spirometry to have a greater certainty in the diagnosis. The objective of this article was to conduct an in-depth review of the controversies in the diagnosis of COPD. During the past years, COPD definition has been updated in different times; however, it is now considered more as a complex syndrome with systemic participation, requiring a multidimensional assessment, and not only a spirometry. (REV INVEST CLIN. 2019;71:28-35)
\end{abstract}

Key words: Chronic obstructive pulmonary disease. Case finding. Screening.

\section{INTRODUCTION}

Sixty years ago, the term "emphysema" in the United States was equivalent to "chronic bronchitis" in Great Britain; to avoid confusion, the former was considered an anatomopathological diagnosis, while the latter was a clinical diagnosis. This underscores

Corresponding author:

*Rogelio Pérez-Padilla

Department of Research in Tobacco and COPD

Instituto Nacional de Enfermedades Respiratorias

Ismael Cosío Villegas (INER)

Calzada de Tlalpan, 4502

Col. Sección XVI, Del. Tlalpan

C.P. 14080, Mexico City, Mexico

E-mail: perezpad@gmail.com the controversy that has since existed to define and diagnose the disease named chronic obstructive pulmonary disease (COPD). COPD is one of the main causes of morbidity and mortality in the world ${ }^{1}$. Today, it is the third most important non-transmissible disease, representing $5.3 \%$ of all deaths worldwide ${ }^{2}$.
Received for publication: 07-06-2018

Approved for publication: 21-09-2018 doi: $10.24875 /$ RIC.18002626 


\section{INFORMATION SEARCH}

We searched for manuscripts published and indexed in PubMed under the following terms: "COPD" or "COPD" and "diagnosis" and "definition" excluding "asthma" and "overlap syndrome," considering review articles and clinical practice guidelines published during the past 10 years. We obtained 97 articles relevant for the purpose.

\section{Definition}

According to the definition proposed by the Global Initiative for Chronic Obstructive Lung Disease (GOLD) in the Global Strategy for the Diagnosis, Management, and Prevention of Chronic Obstructive Lung Disease, 2017 update, "COPD is a common, preventable, and treatable disease that is characterized by persistent respiratory symptoms and airflow limitation that is due to airway and/or alveolar abnormalities usually caused by significant exposure to noxious particles or gases ${ }^{1}$."

COPD definition has been changed during the years. Today, it is accepted that COPD is not only a single clinical entity but also is considered a complex syndrome, resulting from the chronic exposure to one or more noxious agents that are known and that generate a different clinical course ${ }^{1}$. The definition of COPD has included a functional component, centered originally on the progressive and accelerated decline in lung function in individuals who smoke, and now on irreversible airflow obstruction, as clearly airflow obstruction may occur by the hastened decline of forced expiratory volume in 1 second $\left(\mathrm{FEV}_{1}\right)$ or by abnormal growth and development of the lung ${ }^{3}$. At least in epidemiological studies, individuals with irreversible airflow obstruction without relevant exposures are included in the COPD category, which may give rise to confusion. In addition to functional abnormalities, individuals with COPD present varying degrees of emphysema and chronic bronchitis. This complex syndrome is characterized by inflammation not only of the lungs and airways but also systemic ${ }^{4}$, which leads to an increased risk of comorbidity, functional deterioration, as well as limitations in performing daily life activities and decrease in the health-related quality of life ${ }^{5}$.

Risk factors for COPD include a deficiency of natural antiproteases ( $\alpha 1$-antitrypsin or antiprotease); exposure to tobacco, biomass, or industrial smoke; previous pulmonary infections; asthma; and abnormal pulmonary development caused by prenatal or early life events ${ }^{6}$. The majority of cases of COPD in the developed world are related to tobacco consumption; thus, its importance should be emphasized as a definite and preventable cause of the disease. However, about one-third of patients with COPD, or more correctly with irreversible airflow obstruction, are individuals who never smoked?

COPD has been clinically defined by the presence of some cardinal symptoms that include dyspnea, cough, and sputum production ${ }^{6,8,9}$. GOLD's Global Strategy for the Diagnosis, Management, and Prevention of COPD, in its most recent 2017 update, mentions that the diagnosis of COPD should be considered in all individuals with dyspnea, chronic cough, or phlegm and/or exposure to any of the risk factors for the disease ${ }^{1}$. However, recent studies have demonstrated that some subjects who are smokers experience symptoms similar to those observed in patients with COPD - they even exhibit episodes resembling a COPD exacerbation - but without airflow obstruction ${ }^{6}$. In some of these patients, computed tomography (CT) of the thorax has demonstrated pulmonary emphysema; although these individuals do not fulfill the diagnostic criteria of COPD proposed by GOLD, they have a pulmonary disease associated with smoking or with another exposure (Fig. 1) ${ }^{10}$. Due to the possible progression to airflow limitation, this disorder was named "pre-COPD"," which was recognized by GOLD since 2006 as Stage 0. However, this questionable term disappeared in future revisions, since not all subjects with GOLD 0 (or pre-COPD) will develop airflow obstruction ${ }^{11}$.

We aimed for the identification of COPD endotypes, i.e., groups of similar patients according to a multidimensional evaluation of the disease, including several aspects: clinical, physiological, immunological, pathological, genetic, exposure, prognostic, and different response to treatment ${ }^{6,12}$

\section{SPIROMETRIC DEFINITION OF COPD}

The demonstration of airflow obstruction is an indispensable criterion for diagnosing COPD, and the gold standard is the finding by spirometry of a reduced 
Figure 1. A: 60-year-old male with chronic obstructive pulmonary disease diagnosis. History of smoking for 35 years, 20 ciga-

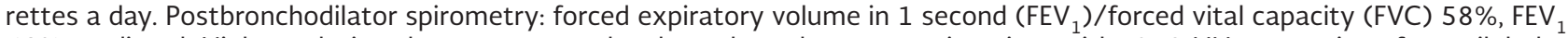
$68 \%$ predicted. High resolution thorax tomography shows hypodense areas in apices with -950 UH suggestive of centrilobular and paraseptal emphysema. B: 51-year-old male with chronic cough and dyspnea. History of smoking for 28 years, 16 cigarettes a day. Postbronchodilator spirometry: FEV1/FVC 74\%, FEV1 92\% predicted. High resolution thorax tomography shows hypodense areas in apices with $-950 \mathrm{UH}$ suggestive of centrilobular and paraseptal emphysema.

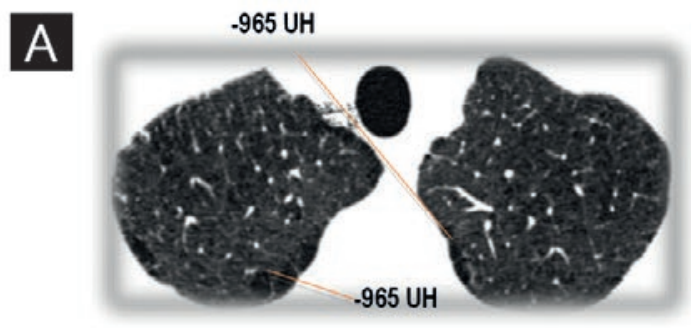

$-980 \mathrm{UH}$
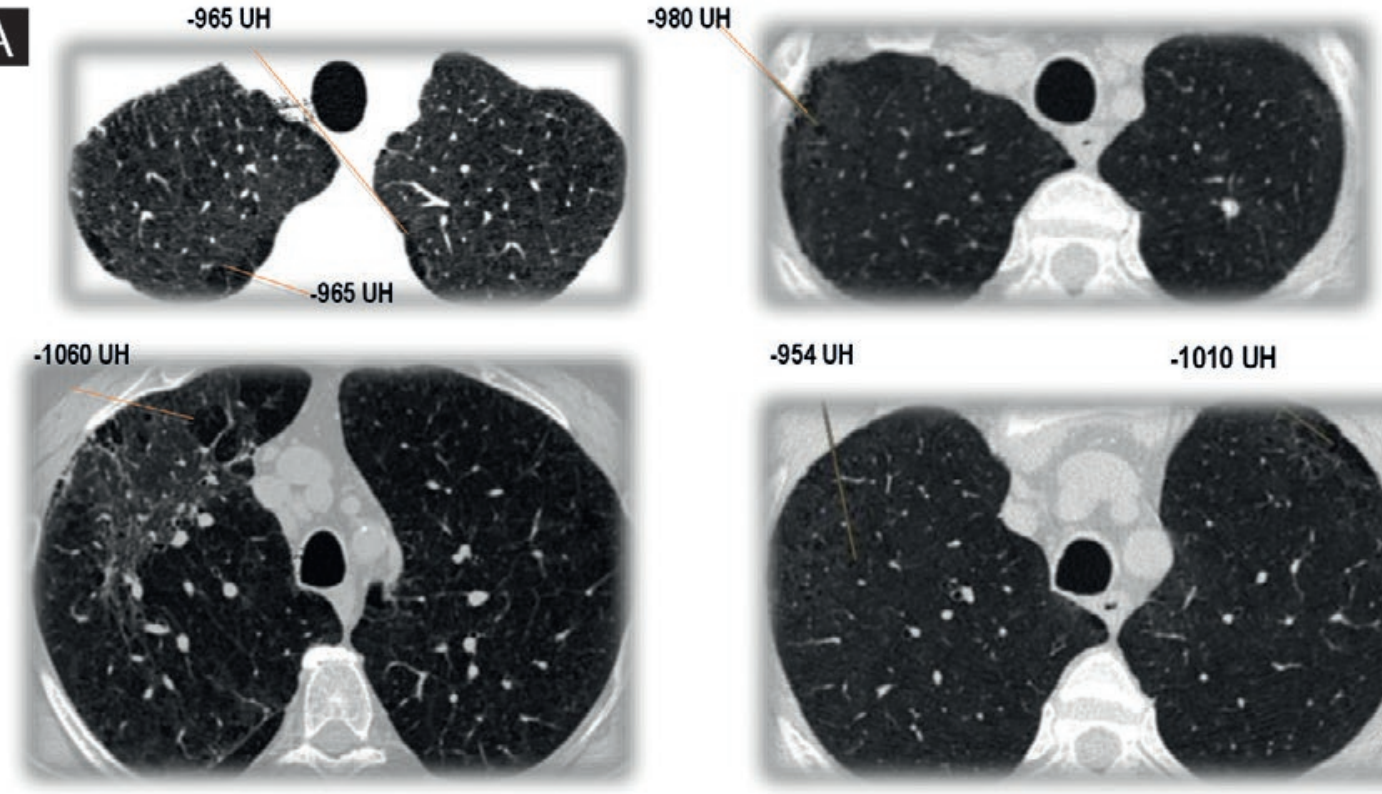

B
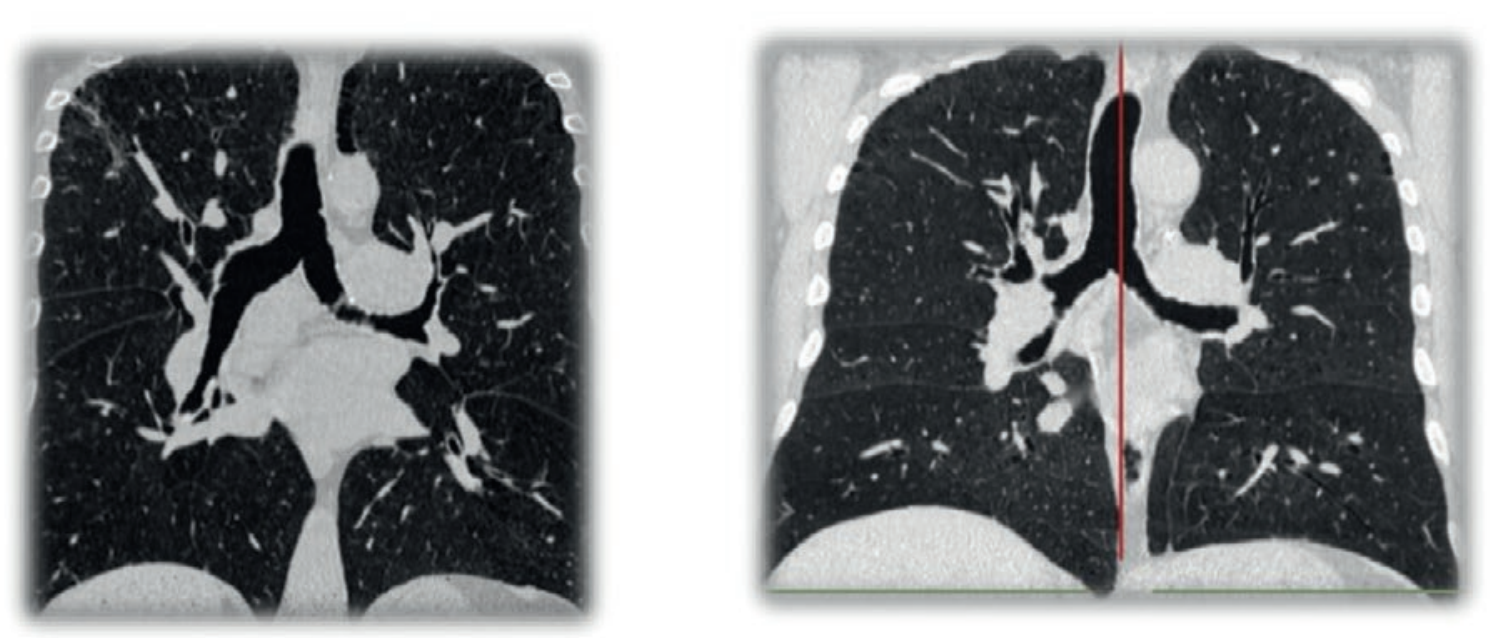

forced expiratory volume in 1 second and forced vital capacity $\left(\mathrm{FEV}_{1} / \mathrm{FVC}\right.$ ) quotient. There is controversy regarding the cut-off point of this quotient that should be used to define obstruction. GOLD defines obstruction as a $\mathrm{FEV}_{1} / \mathrm{FVC}<0.70$, whereas the most common proposed alternative is to use the lower limit of normal (LLN) (the lower $5^{\text {th }}$ percentile), derived from reference values that adjust for age and

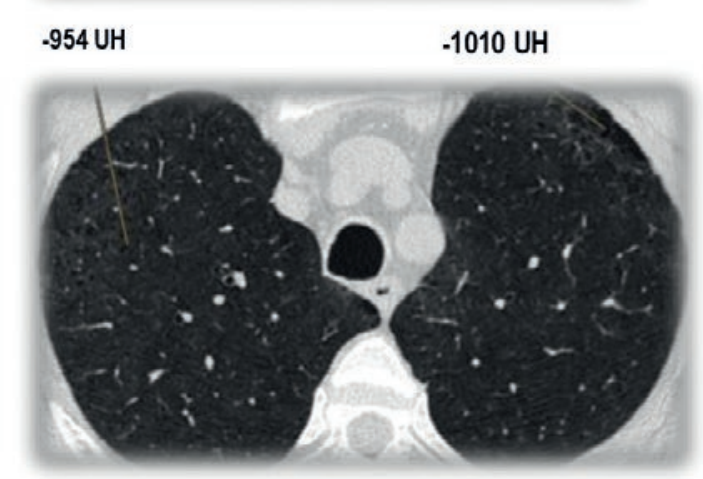

sex. Table 1 shows some definitions of airflow obstruction used in the past.

The 6-s spirometry has been proposed as a simplified alternative to an FVC maneuver because it has the advantage of standardizing the measurement time of the denominator, since the FVC may be measured using good-quality tests at different times and give 
Table 1: Spirometric definitions of COPD

\begin{tabular}{ll}
\hline Organization & Criterion to establish obstruction (COPD) \\
\hline${\text { GOLD } 2017^{\mathrm{a}}}^{\mathrm{a}}$ & Post-BD FEV $_{1} / \mathrm{FVC}<0.7$ \\
ATS/ERS $2004^{\mathrm{b}}$ & Post-BD FEV $_{1} / \mathrm{FVC}<\mathrm{LLN}$ \\
ATS $1995^{\mathrm{c}}$ & $\mathrm{FEV}_{1} / \mathrm{FVC}<5^{\text {th }}$ percentile \\
BTS $^{\mathrm{d}}$ & Post-BD FEV $_{1} / \mathrm{FVC}<0.7$ \\
Alternative & Post-BD FEV $_{1} / \mathrm{FEV}_{6}<\mathrm{LLN}$ \\
\hline
\end{tabular}

FEV $_{1}$ : forced expiratory volume in 1 second; FVC: forced vital capacity, FEV 6 : forced expiratory volume in 6 seconds; LLN: lower limit of normal ( $5^{\text {th }}$ percentile).

aGlobal initiative for chronic obstructive lung disease. Global strategy for the diagnosis, management, and prevention of chronic obstructive pulmonary disease. 2017.

bStandards for the diagnosis and treatment of patients with COPD: a summary of the ATS/ERS position paper. Eur Respir J. 2004;23(6):932-46. ATS; American Thoracic Society. ERS; European Respiratory Society.

${ }^{\mathrm{d} C h r o n i c ~ o b s t r u c t i v e ~ p u l m o n a r y ~ d i s e a s e ~ i n ~ o v e r ~ 16 s: ~ d i a g n o s i s ~ a n d ~ m a n a g e m e n t . ~ N I C E ~ C l i n i c a l ~ G u i d e l i n e s, ~ 2010 . ~ B r i t i s h ~ T h o r a c i c ~ S o c i e t y . ~}$ COPD: chronic obstructive pulmonary disease

different results ${ }^{13}$. The quotient of the $\mathrm{FEV}_{1} / \mathrm{FEV}_{6}$ test is nearly equivalent to the $\mathrm{FEV}_{1} / \mathrm{FVC}$ for COPD diagnosis ${ }^{14,15}$; however, the former is more reproducible, the required maneuver causes less fatigue, and it is possibly more specific than the $\mathrm{FEV}_{1} / \mathrm{FVC}$. There are fewer available reference values for $\mathrm{FEV}_{6}$ and $\mathrm{FEV}_{1} /$ $\mathrm{FEV}_{6}$ in comparison with the current gold standards FVC and $\mathrm{FEV}_{1} / \mathrm{FVC}$.

\section{GOLD CRITERION VERSUS THE LLN}

According to GOLD 2017, an $\mathrm{FEV}_{1} / \mathrm{FVC}$ quotient of < 0.70 after the bronchodilator test confirms the existence of a persistent airflow limitation and identifies the presence of COPD in patients with compatible symptoms and risks ${ }^{1}$. This criterion has been employed in numerous clinical assays and is independent of reference values ${ }^{16}$. However, in healthy persons, $\mathrm{FEV}_{1} / \mathrm{FVC}$ decreases with age, a situation not considered by that criterion. The fixed cut-off point of 0.70 can cause errors in diagnosis at the extremes of life, resulting in underdiagnosis in young adults (false negatives) and overdiagnosis in older adults (false positives that increase disproportionately with age $)^{17-19}$. Thus, the prevalence of COPD by that definition is higher than the one estimated by the statistical criterion of $<$ LLN or less than the $5^{\text {th }}$ percentile $(20.1 \%$ vs. $14.7 \%$ in the PLATINO study $)^{20}$. The high rate of false positives in older adults may cause drug overprescription, adverse effects of medication, excessive use of resources confirming or ruling out the diagnosis, and disease labeling of healthy individuals. The $\mathrm{FEV}_{1} / \mathrm{FVC}$
$<$ LLN criterion to identify obstruction is more specific, reducing the rate of false-positives; however, the LLN depends on the equation of reference used for the post-bronchodilator values that are being employed. In some populations, it will be necessary to develop spirometry reference values if those currently available do not adequately fit the population ${ }^{18}$.

The criteria for defining obstruction should influence prognosis and not only be based on a statistical criterion. In this perspective, the cut-off point would be that which identifies an increased benefit or treatment and a deteriorated prognosis without a disproportionate rise in false-positives. The $\mathrm{FEV}_{1}$, per se, has demonstrated to be a strong prognostic indicator, and in groups with reduced FEV $_{1}$ (such as GOLD stages 2-4), a worse prognosis would be expected. Patients with $\mathrm{FEV}_{1} / \mathrm{FVC}<0.7$ tend to have a lower $\mathrm{FEV}_{1}$ than those with an $\mathrm{FEV}_{1} / \mathrm{FVC}$ of $>0.7$, and adults with $\mathrm{FEV}_{1} / \mathrm{FVC}<\mathrm{LLN}$ an $\mathrm{FEV}_{1}$ lower than individuals with $\mathrm{FEV}_{1} / \mathrm{FVC}<0.7$.

\section{PRE- OR POST-BRONCHODILATOR SPIROMETRY?}

The assessment of airflow obstruction should be done with the spirometry performed after the use of bronchodilators, to lower the contribution of asthma and other causes of reversible obstruction. In the PLATINO study, it was demonstrated that the bronchodilator test reduced by $35 \%$ (from $21.7 \%$ to $14 \%$ ) the prevalence of COPD by using the FEV $1 /$ FVC $\%<0.70$ 
criteria, while when using the $\mathrm{FEV}_{1} / \mathrm{FVC}<\mathrm{LLN}$ criterion, the reduction was $37 \%$ (from $17.4 \%$ to $10.8 \%$ ) $^{20}$. The latter provides more certainty in the clinical diagnosis of COPD. Despite what has been discussed, the pre-bronchodilator spirometry is frequently used to assess bronchial obstruction in patients in whom COPD is suspected.

\section{ONE OR MORE SPIROMETRY TESTS FOR THE DIAGNOSIS OF COPD?}

In daily clinical practice, the diagnosis of COPD is based on the results obtained in the initial spirometry. To date, there is no recommendation by GOLD guidelines, to repeat the forced spirometry to increase consistency and certainty in the diagnosis. However, the $\mathrm{FEV}_{1}$ and the FVC, their ratio, and all tests, for that matter, vary over time even in healthy subjects. For example, the annual variability reported for the $\mathrm{FEV}_{1}$ and the FVC is of $\pm 15 \%$. In up to $22 \%$ of subjects with a baseline spirometry showing obstruction, their tests normalized during the $1^{\text {st }}$ year of follow-up and, after 2 years, the percentage increased to $24-32 \%{ }^{21}$. These results demonstrate that a longitudinal spirometric evaluation could increase certainty in the diagnosis, mainly in patients with borderline values independently of the reference values and diagnostic criteria employed.

\section{CT SCANNING AND DIFFUSING CAPACITY TO IDENTIFY EMPHYSEMA AND ITS RELATION WITH COPD}

Emphysema is defined as "an abnormal and permanent dilation of the air spaces that occur distally to the terminal bronchioles and that is accompanied by the destruction of the interalveolar septa, without evidence of fibrosis ${ }^{10}$." High-resolution CT (HRCT) of the thorax and low-dose tomography of the thorax allow to identify areas of attenuation with $<-950 \mathrm{UH}$, which are consistent with emphysema.

HRCT is the method of choice for diagnosing pulmonary emphysema in vivo ${ }^{22}$, due to greater spatial resolution compared with the conventional tomography of the thorax ${ }^{23}$. Quantitative analysis of lung density measured by HRCT permits to evaluate the degree of extension of emphysema; however, this depends to a great extent on the subjective and visual evaluation of the radiologist ${ }^{24}$. It is now possible to perform a more objective evaluation using tools and software to carry out measurements such as the emphysema index (EI), which defines the relation between the volume of emphysema and total lung volume after a three-dimensional reconstruction. Other indicators include the pixel index (PI), defined as the percentage of pixels with an attenuation of $<-900 \mathrm{UH}$, as well as the $\mathrm{El}$ in expiration (Elex), $\mathrm{Pl}$ in maximum expiration (Plex), and the pulmonary blood flow (BF) ${ }^{25,26}$. The sensitivity of the El in the HRCT is 0.80 ( $95 \%$ confidence interval $[\mathrm{Cl}], 0.74-0.84$ ), while when the tomographic signs (El, Plex, Elex, and BF) are combined, the sensitivity for detecting emphysema rises up to 0.87 (95\% Cl, 0.64-0.96) $)^{25}$. In comparison with inspiration, CT measurements in expiration are tightly correlated with airflow obstruction; however, this exposes the patients to additional radiation ${ }^{26}$.

The use of low-dose CT (20-40 mA) with a slice thickness of $1.25 \mathrm{~mm}$ allows for the identification of pulmonary emphysema with accuracy, in addition to permitting the graduation of its extension and correlating it with the histopathological pattern (centrilobular or paraseptal). Likewise, it is possible to identify other typical findings in smoker patients, such as interstitial lung disease, bronchiectasis, and calcification in the coronary arteries or aorta. Lowdose CT can decrease the amount of global radiations for the quantitative evaluation of emphysema, without losing diagnostic value ${ }^{10,26}$. In a recent study that included smokers with normal spirometry, it was demonstrated that $75 \%$ of the participants had emphysema detected in the low-dose CT of the thorax. Although the extension of the emphysema was mild, those findings were associated with a lower quality of life, low $\mathrm{DL}_{\mathrm{co}}$, a greater number of exacerbations in the previous year, and a significant fall in oxygen saturation during the 6 -minute walk test (6MWT) ${ }^{10}$. Despite the benefits of the CT, no guidelines, to our knowledge, recommend its routine use, due to the exposure to radiation and to its considerable cost.

A single-breath carbon monoxide diffusing capacity $\left(D_{L C O}\right)$ and a spirometry below $L L N$ values suggest the presence of emphysema ${ }^{27}$. In patients with pulmonary emphysema, it has been demonstrated that the $D_{L C O}$ is proportional to the extension of the emphysema 
and correlates with lower resting $\mathrm{PaO}_{2}$, as well as a greater requirement of supplementary oxygen, fewer meters in the 6MWT, and lower maximum exercise capacity ${ }^{28}$.

\section{RESPIRATORY SYMPTOMS AND COPD}

Recently, the relevance of respiratory symptoms has been emphasized since they can predict a poor prognosis, an accelerated decrease in lung function, and exacerbations. Various symptom questionnaires have been developed, including COPD assessment test (CAT) and COPD questionnaire score ${ }^{29}$. The CAT questionnaire is a sensitive, simple, and quick tool for assessing the respiratory status of COPD patients ${ }^{30}$. The new GOLD classification incorporates the symptoms (CAT score $>10$ and mMRC dyspnea score $>2$ ) and the frequency or severity of exacerbations for therapeutic decisions ${ }^{1}$. The combination of a long-acting bronchodilator (LABA) and longacting muscarinic antagonist (LAMA) is recommended for patients classified as GOLD Groups B or $C$ with persistent symptoms after bronchodilator monotherapy with LAMA or LABA ${ }^{31}$. This combination reduces symptoms and exacerbations compared with LAMA or LABA monotherapy ${ }^{32}$. However, the classification by symptoms is more unstable and less of a prognostic factor than that based on spirometry ${ }^{33}$ and, according to current GOLD classification ${ }^{1}$, can give rise to the prescription of expensive LABA to persons with minimal obstruction, with borderline obstruction, or even to false positives, very frequent in mild COPD such as GOLD stage 1 in older individuals. Respiratory symptoms (cough, phlegm, dyspnea, and wheezing) may have a variety of causes and should be investigated as any other symptom before assuming that they are caused solely by COPD and that will respond to bronchodilators. In population-based studies, those symptoms are associated with smoking, passive smoking, and exposure to occupational agents, as well as with asthma diagnosis, with spirometry abnormalities (obstructive and restrictive), and with self-reported cardiac disease, but a long list of causes is known. The use of questionnaires applied by the clinician, compared to those self-answered by the patient, reduces the number of diagnostic evaluations necessary to identify a COPD patient ${ }^{2,34}$.

\section{MULTIDIMENSIONAL INDICATORS IN COPD}

Multidimensional indicators are increasingly used not only for the diagnosis of COPD but also for prognosis. These indexes have greater prognostic value in comparison with the isolated spirometry measurement ${ }^{35}$. The body mass index, airflow obstruction, dyspnea score, and exercise (BODE) index (acronym for BODE capacity) has demonstrated to be better than $\mathrm{FEV}_{1}$ for predicting the risk of death due to any cause and due to respiratory causes in patients with COPD ${ }^{36}$, which is to be expected up to a certain point in that it incorporates multiple domains of the disease and is expected to vary less over time ${ }^{37,38}$.

\section{DETECTION OF COPD IN THE COMMUNITY AND PRIMARY CARE}

In the general population, there is an enormous underdiagnosis of COPD that can rise to $90 \%$ when the spirometry definition is used ${ }^{39}$. The number of spirometry tests conducted in primary care has increased very little, even in developed countries, and in some reports, in only $12.2 \%$ of patients with clinical symptoms suggestive of COPD, a spirometry is performed to confirm the diagnosis ${ }^{40-42}$.

There is a lack of scientific evidence to define the best procedures for the timely detection of COPD, especially in high-risk groups, i.e., "case finding." Case finding is a strategy whereby resources are focused on individuals or groups suspected of being at risk for a specific disease, instead of considering the whole population. It implies the active and systematic search for persons at risk instead of waiting for the presentation of the symptoms or signs of active disease. Accumulated smoking (pack-years) is the most important risk factor for airflow obstruction; therefore, the presence of smoking (especially in older men) is a common requisite for selecting individuals for case finding, given that the higher the level of smoking, the prevalence of COPD will also rise in the selected group ${ }^{43,44}$. The best detection strategy will probably vary according to the country, region, and characteristics of the population and of the health system ${ }^{34}$. The symptoms and exposures can be explored rapidly with questionnaires, selecting individuals 
considered at high risk for the spirometry. An intermediate step with a simplified lung function test (peak flow or 6-s spirometry) can increase availability and reduce the number of spirometry tests, a strategy that is, especially, efficient if the objective is to identify moderate-to-severe obstruction ${ }^{39}$.

A program for the active search of COPD in its preclinical stage requires an important assignment of resources; thus, at present, it is considered that, in asymptomatic never smokers or in individuals unexposed to other noxious factors, a screening spirometry is not recommended. Spirometry should be performed preferably on symptomatic patients, older than 40 years of age, with risk factors such as smoking, especially if they smoked $>10$ (or 20) pack-years or had other exposure risks such as substantial exposure to biomass smoke or occupational dusts or smokes. In this scenario, up to one in five subjects will have COPD, a number that increases to one of every three subjects in those of higher age and with greater exposure to tobacco. With fewer symptoms, age, or exposures, the number of spirometries performed to identify one individual with airflow obstruction increases progressively and can be cost-ineffective.

In Latin America, the PLATINO study (Proyecto Latinoamericano de Investigación de la Enfermedad Pulmonar Obstructiva, Latin-American Project of Investigation in Obstructive Pulmonary Disease) showed a prevalence of COPD of $14.3 \%$ with the GOLD criterion $\left(\mathrm{FEV}_{1} / \mathrm{FVC}<0.70\right.$ ), of whom nearly $90 \%$ had no medical diagnosis, that is, $90 \%$ of patients with COPD did not know that they had the disease ${ }^{33,45}$. The main factors for an underdiagnosis of COPD were a younger age, mild obstruction, fewer respiratory symptoms, and importantly, the lack of a spirometry test ${ }^{42}$.

In the PUMA study (prevalence study and regular practice, diagnosis, and treatment, among general practitioners in populations at risk of COPD in Latin America), at-risk subjects were included if they were $\geq 40$ years old, current or ex-smokers ( $\geq 10$ packyears), and/or with exposure to biomass smoke (wood or coal, for cooking or heating; exposure $\geq 100$ $\mathrm{h} /$ year). The COPD prevalence in this study was $20.1 \%$ and $14.7 \%$ using post-BD FEV $_{1} /$ FVC $<0.70$ and LLN definitions, respectively ${ }^{43}$.

\section{CONCLUSION}

The current definition of COPD includes a post-bronchodilator spirometry in subjects with exposures and risk factors, although the cut-off point to define obstruction varies, generating definitions with more or less specificity. While the present-day guidelines recommend a single spirometry test, the variability of the latter, particularly in borderline tests, requires an observation over time and the performance of repeated tests. The $\mathrm{FEV}_{1} / \mathrm{FEV}_{6}$ index is more reliable than the FEV1/FVC, specifically when groups with spirometries with a different expiratory time are compared.

\section{REFERENCES}

1. Vogelmeier CF, Criner GJ, Martinez FJ, et al. Global strategy for the diagnosis, management, and prevention of chronic obstructive lung disease 2017 report. Gold executive summary. Am J Respir Crit Care Med. 2017;195:557-82.

2. Haroon S, Jordan R, Takwoingi Y, Adab P. Diagnostic accuracy of screening tests for COPD: a systematic review and metaanalysis. BMJ Open. 2015;5:e008133.

3. Lange $P$, Celli B, Agustí A, et al. Lung-function trajectories leading to chronic obstructive pulmonary disease. N Engl J Med. 2015;373:111-22.

4. Eagan TM, Ueland T, Wagner PD, et al. Systemic inflammatory markers in COPD: results from the Bergen COPD cohort study. Eur Respir J. 2010;35:540-8.

5. Agustí A, Edwards LD, Rennard SI, et al. Persistent systemic inflammation is associated with poor clinical outcomes in COPD: a novel phenotype. PLoS One. 2012;7:e37483.

6. Celli BR, Agustí A. COPD: time to improve its taxonomy? ERJ Open Res. 2018;4:00132-2017.

7. Pérez-Padilla R, Fernández R, López Varela MV, et al. Airflow obstruction in never smokers in five Latin American cities: the PLATINO study. Arch Med Res. 2012;43:159-65.

8. Woodruff PG, Barr RG, Bleecker E, et al. Clinical significance of symptoms in smokers with preserved pulmonary function. $\mathrm{N}$ Engl J Med. 2016;374:1811-21.

9. Rodriguez-Roisin R, Han MK, Vestbo J, Wedzicha JA, Woodruff PG, Martinez FJ. Chronic respiratory symptoms with normal spirometry. A reliable clinical entity? Am J Respir Crit Care Med. 2017;195:17-22.

10. Alcaide AB, Sanchez-Salcedo P, Bastarrika G, et al. Clinical features of smokers with radiological emphysema but without airway limitation. CHEST. 2017;151:358-65.

11. Vestbo J, Lange P. Can GOLD stage 0 provide information of prognostic value in chronic obstructive pulmonary disease? Am J Respir Crit Care Med. 2002;166:329-32.

12. Loscalzo J, Barabasi AL. Systems biology and the future of medicine. Wiley Interdiscip Rev Syst Biol Med. 2011;3:619-27.

13. Pérez-Padilla R, Wehrmeister FC, Celli BR, et al. Reliability of FEV1/FEV6 to diagnose airflow obstruction compared with FEV1/FVC: the PLATINO longitudinal study. PLoS One. 2013; 8:e67960.

14. Jing J, Huang T, Cui W, Xu F, Shen H. Should FEV1/FEV6 replace FEV1/FVC ratio to detect airway obstruction?: a metaanalysis. Chest. 2009;135:991-8.

15. Swanney MP, Jensen RL, Crichton DA, Beckert LE, Cardno LA, Crapo RO. FEV6 is an acceptable surrogate for FVC in the spirometric diagnosis of airway obstruction and restriction. Am J Respir Crit Care Med. 2000;162:917-9.

16. Bhatt SP. Diagnosis of chronic obstructive pulmonary disease: breathing new life into an old debate. Ann Am Thorac Soc. 2018;15:163-5.

17. van Dijk W, Tan W, Li $P$, et al. Clinical relevance of fixed ratio vs lower limit of normal of FEV1/FVC in COPD: patient-reported outcomes from the can cold cohort. Ann Fam Med. 2015;13:41-8. 
18. Güder G, Brenner S, Angermann CE, et al. GOLD or lower limit of normal definition? A comparison with expert-based diagnosis of chronic obstructive pulmonary disease in a prospective cohort-study. Respir Res. 2012;13:13.

19. Wollmer P, Engström G. Fixed ratio or lower limit of normal as cut-off value for FEV1/VC: an outcome study. Respir Med. 2013;107:1460-2.

20. Pérez-Padilla R, Hallal PC, Vázquez-García JC, et al. Impact of bronchodilator use on the prevalence of COPD in populationbased samples. COPD. 2007;4:113-20.

21. Pérez-Padilla R, Wehrmeister FC, Montes de Oca M, et al. Instability in the COPD diagnosis upon repeat testing vary with the definition of COPD. PLoS One. 2015;10:e0121832.

22. Choromańska A, Macura KJ. Role of computed tomography in quantitative assessment of emphysema. Pol J Radiol. 2012; 77:28-36

23. Milne $S$, King GG. Advanced imaging in COPD: insights into pulmonary pathophysiology. J Thorac Dis. 2014;6:1570-85.

24. Lee YK, Oh YM, Lee JH, et al. Quantitative assessment of emphysema, air trapping, and airway thickening on computed tomography. Lung. 2008;186:157-65.

25. Li J, Zhang H, Bai Y, et al. Diagnostic value of computed tomography in chronic obstructive pulmonary disease: a systematic review and meta-analysis. COPD J Chronic Obstruct Pulm Dis. 2012;9:563-70.

26. Xie $X$, Jong PA de, Oudkerk $M$, et al. Morphological measurements in computed tomography correlate with airflow obstruction in chronic obstructive pulmonary disease: systematic review and meta-analysis. Eur Radiol. 2012;22:2085-93.

27. Cotton DJ, Soparkar GR, Graham BL. Diffusing capacity in the clinical assessment of chronic airflow limitation. Med Clin. 1996; 80:549-64.

28. Mohsenifar Z, Lee SM, Diaz P, et al. Single-breath diffusing capacity of the lung for carbon monoxide: a predictor of $\mathrm{PaO} 2$, maximum work rate, and walking distance in patients with emphysema. Chest. 2003;123:1394-400.

29. Sundh J, Janson C, Lisspers K, Montgomery S, Ställberg B. Clinical COPD questionnaire score (CCQ) and mortality. Int J Chron Obstruct Pulmon Dis. 2012;7:833-42.

30. Negro RW, Bonadiman L, Turco P. Sensitivity of the COPD assessment test (CAT questionnaire) investigated in a population of 681 consecutive patients referring to a lung clinic: the first Italian specific study. Multidiscip Respir Med. 2014;9:15.

31. Anzueto A, Miravitlles M. Considerations for the correct diagnosis of COPD and its management with bronchodilators. Chest. 2018;154:242-8

32. Thomas M, Halpin DM, Miravitlles M. When is dual bronchodilation indicated in COPD? Int J Chron Obstruct Pulmon Dis. 2017; 12:2291-305.
33. Menezes AM, Pérez-Padilla R, Jardim JR et al Chronic obstructive pulmonary disease in five Latin American cities (the PLATINO study): a prevalence study. Lancet. 2005;366:1875-81.

34. Haroon SM, Jordan RE, O'Beirne-Elliman J, Adab P. Effectiveness of case finding strategies for COPD in primary care: a systematic review and meta-analysis. NPJ Prim Care Respir Med. 2015; 25:15056.

35. Agustí A, Celli B. Natural history of COPD: gaps and opportunities. ERJ Open Res. 2017;3:00117-2017.

36. Celli BR, Cote CG, Marin JM, et al. The body-mass index, airflow obstruction, dyspnea, and exercise capacity index in chronic obstructive pulmonary disease. N Engl J Med. 2004;350: 1005-12.

37. Puhan MA, Garcia-Aymerich J, Frey M, et al. Expansion of the prognostic assessment of patients with chronic obstructive pulmonary disease: the updated BODE index and the ADO index. Lancet. 2009;374:704-11.

38. Casanova C, Aguirre-Jaíme A, Torres JP de, et al. Longitudinal assessment in COPD patients: multidimensional variability and outcomes. Eur Respir J. 2014;43:745-53.

39. Pérez-Padilla R, Thirion-Romero I, Guzmán N. Underdiagnosis of chronic obstructive pulmonary disease: should smokers be offered routine spirometry tests? Expert Rev Respir Med. 2018; 12:83-5.

40. Luize AP, Menezes AM, Pérez-Padilla R, et al. Assessment of five different guideline indication criteria for spirometry, including modified GOLD criteria, in order to detect COPD: data from 5,315 subjects in the PLATINO study. NPJ Prim Care Respir Med. 2014:24:14075

41. Moreira GL, Gazzotti MR, Manzano BM, et al. Incidence of chronic obstructive pulmonary disease based on three spirometric diagnostic criteria in Sao Paulo, Brazil: a nine-year follow-up since the PLATINO prevalence study. Sao Paulo Med J. 2015; 133:245-51.

42. Herrera AC, Montes de Oca M, López Varela MV et al. COPD under diagnosis and misdiagnosis in a high-risk primary care population in four Latin American countries. A key to ehance disease diagnosis: the PUMA study. PLoS One. 2016;11: e0152266.

43. López Varela MV, Montes de Oca M, Rey A, et al. Development of a simple screening tool for opportunistic COPD case finding in primary care in Latin America: the PUMA study. Respirology. 2016;21:1227-34

44. Dirven JA, Tange HJ, Muris JW, van Haaren KM, Vink G, van Schayck OC. Early detection of COPD in general practice: implementation, workload and socioeconomic status. A mixed-methods observational study. Prim Care Respir J. 2013;22:338-43.

45. Tálamo C, de Oca MM, Halbert R, et al. Diagnostic labeling of COPD in five Latin American cities. Chest. 2007;131:60-7. 